\title{
Adverse fetal outcomes and its associated factors in Ethiopia: a systematic review and meta-analysis
}

\author{
Getnet Gedefaw $^{1 *}$ (D), Birhan Alemnew ${ }^{2}$ and Asmamaw Demis ${ }^{3}$
}

\begin{abstract}
Background: Despite the reduction of neonatal morbidity and mortality, is one of the third Sustainable Development Goal to end the death of children, the burden of the problem still the major challenge in Ethiopia. Globally, the most common causes of neonatal morbidity and mortality are adverse fetal outcomes (low birth weight, stillbirth, prematurity, congenital defect). Therefore this systematic review and meta-analysis aimed to estimate the pooled prevalence of adverse fetal outcomes and its associated factors in Ethiopia.
\end{abstract}

Method: International databases (PubMed, Google scholar, web of science and science direct) were searched. Seventeen articles were included, among these, fourteen were cross-sectional and three of them were case-control studies. Publication bias was employed using a funnel plot and eggers test. The $\mathrm{I}^{2}$ statistic was computed to check the heterogeneity of studies. Subgroup analysis was performed for the evidence of heterogeneity.

Result: A total of 11,280 study participants were used to estimate the pooled prevalence of adverse fetal outcomes. The overall pooled prevalence of adverse fetal outcomes in Ethiopia was 26.88\% (95\% Cl; 20.73-33.04). Low birth weight $10.06 \%(95 \% \mathrm{Cl} ; 7.21-12.91)$ and prematurity $8.76 \%(95 \% \mathrm{Cl} ; 5.4-12.11)$ were the most common adverse birth outcome at the national level. Rural in residency ( $\mathrm{AOR}=2.31 ; 95 \% \mathrm{Cl}: 1.64-3.24$ ), lack of antenatal care follow up (AOR $=3.84 ; 95 \% \mathrm{Cl}: 2.76-5.35)$, pregnancy-induced hypertension ( $\mathrm{AOR}=7.27 ; 95 \% \mathrm{Cl}: 3.95-13.39$ ), advanced maternal age $\geq 35(\mathrm{AOR}=2.72 ; 95 \% \mathrm{Cl}: 1.62-4.58$, and having current complication of pregnancy $(\mathrm{AOR}=4.98 ; 95 \%$ Cl: $2.24-11.07)$ were the factors associated with adverse birth outcome.

Conclusion: The pooled prevalence of adverse fetal outcomes in Ethiopia was high. Rural in residency, lack of antenatal care follow up, pregnancy-induced hypertension, advanced maternal age $\geq 35$, and having current complications of pregnancy were the factors associated with adverse fetal outcomes.

PROSPERO protocol registration: CRD42020149163.

Keywords: Meta-analysis, Neonatal outcomes, Systematic review

\section{Background}

Adverse fetal outcome is the major challenge both in low and middle-income countries. Globally, adverse birth outcomes such as preterm birth, low birth weight,

\footnotetext{
* Correspondence: gedefawget@gmail.com

${ }^{1}$ Department of Midwifery, College of health sciences, Woldia University, Woldia, Ethiopia

Full list of author information is available at the end of the article
}

stillbirth, and congenital defect are some of the common problems. Neonatal morbidities and mortalities are one of the most common contributing factors for 11.8 million deaths. Even though neonatal mortality is declined globally, highest in sub-Saharan Africa and South Asia, with each estimated at 27 deaths per 1000 live births in 2017 [1].

\section{$\mathrm{BMC}$}

(c) The Author(s). 2020 Open Access This article is licensed under a Creative Commons Attribution 4.0 International License, which permits use, sharing, adaptation, distribution and reproduction in any medium or format, as long as you give appropriate credit to the original author(s) and the source, provide a link to the Creative Commons licence, and indicate if changes were made. The images or other third party material in this article are included in the article's Creative Commons licence, unless indicated otherwise in a credit line to the material. If material is not included in the article's Creative Commons licence and your intended use is not permitted by statutory regulation or exceeds the permitted use, you will need to obtain permission directly from the copyright holder. To view a copy of this licence, visit http://creativecommons.org/licenses/by/4.0/ The Creative Commons Public Domain Dedication waiver (http://creativecommons.org/publicdomain/zero/1.0/) applies to the data made available in this article, unless otherwise stated in a credit line to the data. 
Low birth weight is one of the most common causes of neonatal morbidity and mortality worldwide. Globally, low birth weight (LBW) is one of the major neonatal problems that predispose neonates to different neonatal complications, such as hypoglycemia, hypothermia, and different acute and long-term developmental complications [2-6]. Epidemiologically, 15 to $20 \%$ of newborns are low birth weight globally; among this $4.53 \%$ of them are accounted in Ethiopia [7, 8].

Every year, more than 7 million perinatal deaths occur across the world, and half of them are stillbirth's accounts for 3.5 million stillbirths. The rate of stillbirth in developed countries is estimated between 4.2 and 6.8 per 1000 births whereas in low and middle-income countries ranges from 20 to 32 per 1000 births [9-11]. In sub-Saharan Africa, more than 900,000 babies die as stillbirths [12]. Among subSaharan African countries, Ethiopia is a country where the highest proportion of stillbirths has occurred. According to the systematic review done from 1974 to 2013 in Ethiopia showed that the magnitude of stillbirths is $60-110 / 1000$ births [13].

Prematurity is another important risk factor for neonatal complications. Each year estimated 13 million newborns born before 37 weeks of gestation which contributes to $27 \%$ of neonatal deaths; in the world; meaning more than one million preterm babies die each year due to prematurity [14]. Despite the institutional delivery and antenatal care follow up is increasing rapidly still, neonatal death is increasing.

Worldwide, over 303,000 newborns die within 4 weeks of birth every due to congenital anomalies. Congenital anomalies can contribute to long-term disability, which may have significant impacts on individuals, families, and societies. The most common, severe congenital anomalies are heart defects, spinal Bifida, anencephaly, severe hydrocephalus, neural tube defects and Down syndrome [15].

According to 2019 EMDHS, neonatal mortality is increasing to $30 / 1000$ births as compared to 2016 EDHS showed that 29/1000births. Therefore, this systematic review and meta-analysis are aimed to estimate the overall prevalence of adverse birth outcomes (low birth weight, preterm birth, stillbirth, and congenital defect) and secondly identify factors contributing to adverse birth outcomes in Ethiopia.

\section{Methods}

This systematic review and meta-analysis were conducted to estimate the pooled prevalence of adverse fetal outcomes, the most common magnitude of adverse fetal outcomes and associated factors in Ethiopia using the standard PRISMA checklist guideline.

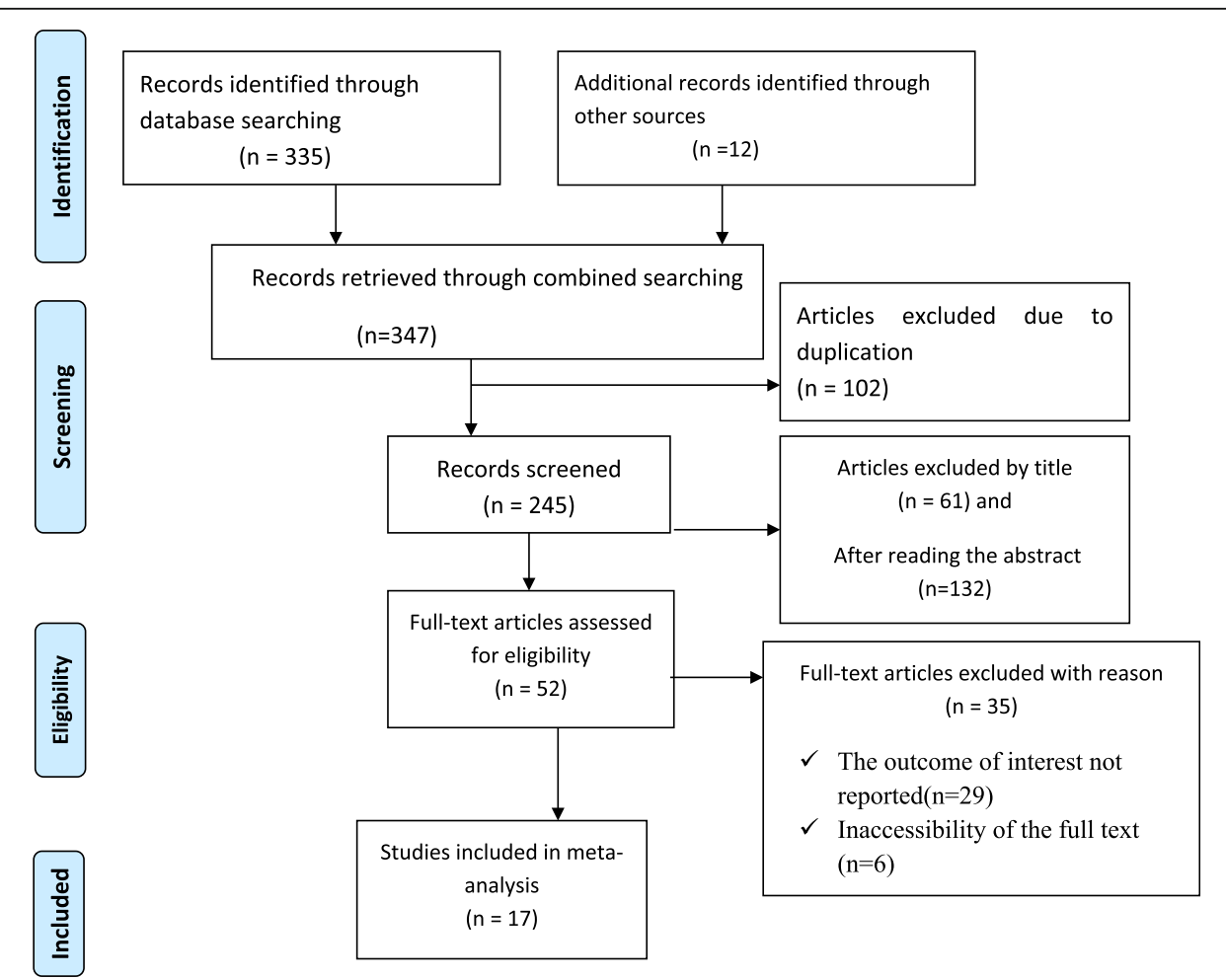

Fig. 1 Flow chart of study selection for systematic review and meta-analysis of adverse fetal outcomes and its associated factors in Ethiopia 
Table 1 Study characteristics included in the systematic review and meta-analysis

\begin{tabular}{|c|c|c|c|c|c|c|c|c|}
\hline Authors & Region & Study area & Study design & Sample size & Prevalence & Response rate & Outcome variables & Quality \\
\hline Abebe Eyowas et al. [21] & Amhara & Bahirdar & cross sectional & 3003 & 37.796 & $100 \%$ & Preterm birth, LBW, Stillbirth & Low ris \\
\hline Ritbano A et al. [22] & SNNPR & Bitajira & cross sectional & 313 & 18.211 & $100 \%$ & Preterm birth, LBW, Stillbirth \& congenital defect & Low \\
\hline Kebede et al. [23] & Amhara & D/tabor & case control & 620 & - & $100 \%$ & - & Low \\
\hline Cherie N, Mebratu A [24] & Amhara & Dessie & cross sectional & 462 & 32.468 & $100 \%$ & Preterm birth, LBW, Stillbirth \& congenital defect & Low 1 \\
\hline Kassa et al. [25] & Amhara & E/gojjam & cross sectional & 1134 & 19.224 & $90.40 \%$ & Preterm birth, LBW, Stillbirth & Low $\mathrm{r}$ \\
\hline Feleke G et al. [26] & SNNPR & Gamo gofa & case control & 420 & - & $98.50 \%$ & - & Low \\
\hline Adane et al. [27] & Amhara & Gondar & cross sectional & 481 & 22.661 & $98.16 \%$ & Preterm birth, LBW, Stillbirth & Low \\
\hline Tsegaye and Kassa [28] & SNNPR & Hawassa & cross sectional & 580 & 18.276 & $100 \%$ & Preterm birth, LBW, Stillbirth \& congenital defect & Low I \\
\hline Abdo et al. [29] & SNNPR & Hossana & cross sectional & 327 & 24.465 & $100 \%$ & Preterm birth, LBW, Stillbirth \& congenital defect & Low \\
\hline Eyosias Yeshialem [30] & Oromia & Jimma & case control & 344 & - & $100 \%$ & - & Low $\mathrm{r}$ \\
\hline Eshete A et al. [31] & Amhara & North wollo & cross sectional & 295 & 23.051 & $100 \%$ & Preterm birth, LBW, Stillbirth \& congenital defect & Low $r$ \\
\hline Ediris et al. [32] & Oromia & Shashemene & cross sectional & 306 & 34.967 & $100 \%$ & Preterm birth, LBW, Stillbirth \& congenital defect & Low \\
\hline Abera Haftu et al. [33] & Tigray & Shire & cross sectional & 425 & 22.588 & 100 & Preterm birth, LBW, Stillbirth & Lon \\
\hline Tsegaye Lolaso [34] & SNNPR & Kembata & cross sectional & 718 & 13.928 & $93 \%$ & Preterm birth,LBW, Stillbirth & Lo \\
\hline Mekonnen $\mathrm{M}$, et al. [37] & Somali & Fafan & cross sectional & 1050 & 51.905 & $98.30 \%$ & Stillbirth, congenital defect & Low \\
\hline Hailemariam Workie [35] & Tigray & Mekelle & Cross sectional & 340 & 25 & $100 \%$ & Preterm birth,LBW, Stillbirth & Low \\
\hline kassahun et al. [36] & Amhara & Woldia & cross sectional & 462 & 31.818 & $100 \%$ & Preterm birth,LBW, Stillbirth & Low \\
\hline
\end{tabular}

\section{Searching strategy}

International databases (Pub Med, Google Scholar, Web of Science), different gray pieces of literature and articles published in the university online repository were included. Core searching terms were used using PICO formulating questions. These were: "newborn", "adverse birth outcome", "fetal outcome", "stillbirth", "low birth weight", "neonate", "prematurity", "congenital anomaly", "congenital defect", "preterm", "preterm birth". "Ethiopia”. The following Searching terms were applied: neonate OR newborn OR women OR infant OR child OR children AND "abnormal birth weight" OR "congenital defect" OR "congenital anomaly" OR "stillbirth" OR "prematurity" OR "preterm birth" OR "low birth weight" OR "perinatal” OR "neonatal death" OR "preterm "AND Ethiopia and related terms. The search strategy has been employed from July 3/2019- September 30/2019.

\section{Inclusion and exclusion criteria}

Observational studies (case-control and cross-sectional) were included. Articles reported the prevalence or/ and a minimum of one contributing factor for adverse fetal outcomes is included. Only English language literature and research articles were included. Studies reported overall adverse fetal outcomes and/or associated factors were included. Whereas, articles without full abstracts or texts and articles reported out of the outcome interest were excluded.

\section{Quality assessment}

Two authors (GG \& AD) independently assessed the quality of each study using the Joanna Briggs Institute
(JBI) quality appraisal checklist was used [16]. Any disagreement was resolved by the hindrance of the third reviewer (BA). The following JBI items used to appraise case-control studies were: [1] comparable groups, [2] appropriateness of cases and controls, [3] criteria to identify cases and controls, [4] standard measurement of exposure, [5] similarity in the measurement of exposure for cases and controls, [6] handling of confounder [7], strategies to handle confounder, [8] standard assessment of outcome, [9] appropriateness of duration for exposure, and [10] appropriateness of statistical analysis. Items used to appraise cross-sectional studies are: [1] inclusion criteria, [2] description of study subject and setting, [3] valid and reliable measurement of exposure, [4] objective and standard criteria used, [5] identification of confounder, [6] strategies to handle confounder, [7] outcome measurement, and [8] appropriate statistical analysis. Therefore to consider the studies have low risk, the value should be $50 \%$ and above the quality assessment indicators.

\section{Data extraction}

After collecting findings from the entire database, the articles were transferred from Endnote version X8 software to the Microsoft Excel spreadsheet to remove duplicated studies. Two authors (AD and GG) independently extracted all the important data using a standardized JBI data extraction format. Any disagreement between reviewers was resolved by the third reviewer (BA) through discussion and consensus. The name of the author, sample size, publication year, study area, response rate region, the overall prevalence of adverse fetal 


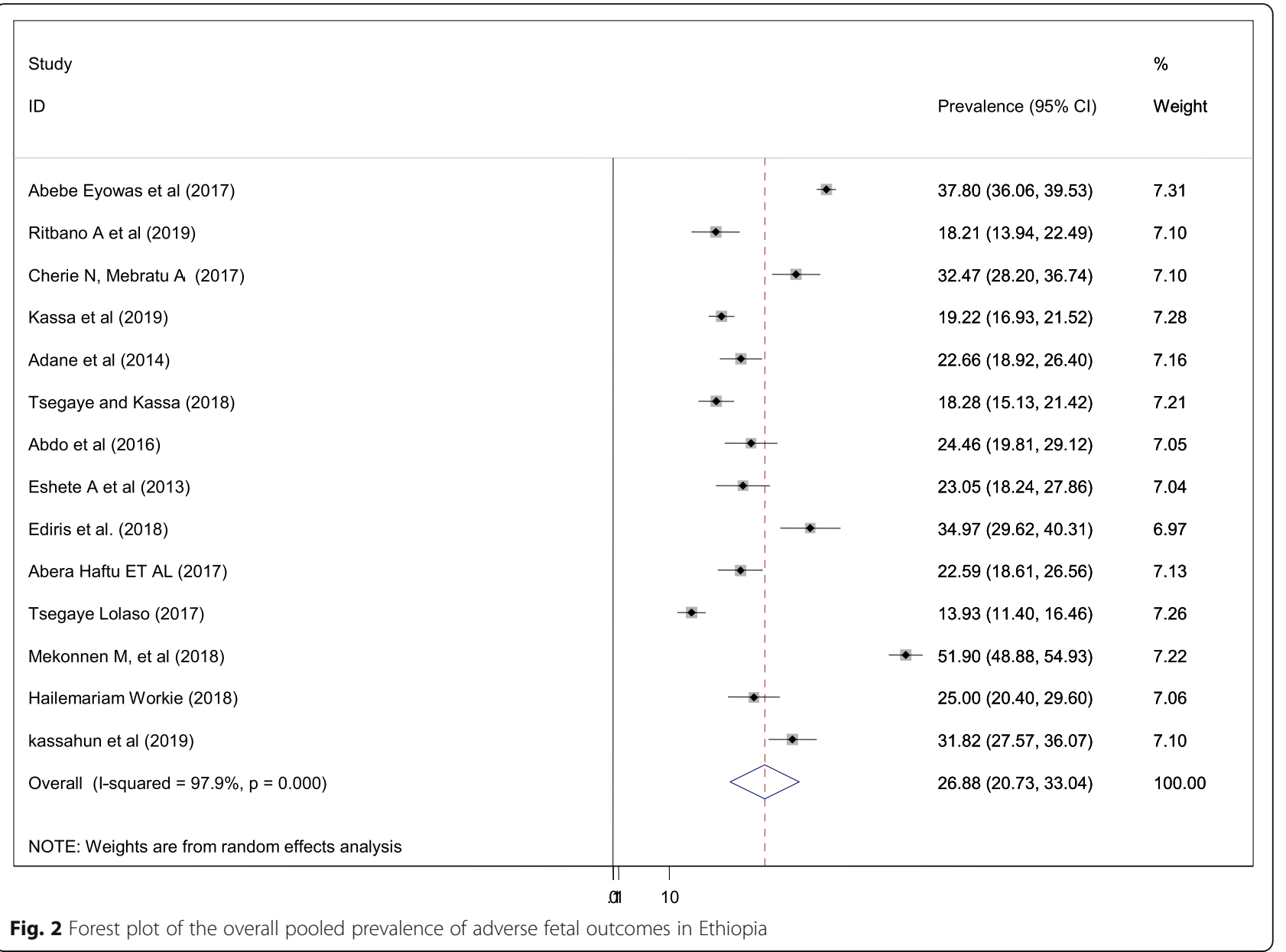

outcome with its outcome categories with $95 \% \mathrm{CI}$ and associated factors were collected.

\section{Outcome of measurements}

Adverse fetal outcome; at least one of the following (stillbirth, low birth weight, preterm and congenital anomaly) was reported.

Stillbirth is the death of the newborn after 28 weeks of gestation and during labor.

Preterm birth/prematurity: as having a Gestational age at the birth of $<37$ weeks.

Congenital anomaly: was considered, when newborn recorded having any body parts of congenital defects.

Low birth weight: was considered, when newborn weight recorded below $2500 \mathrm{~g}$. Moreover, the outcome of this study extends to identify associated factors of adverse birth outcomes.

\section{Data analysis}

Publication bias was checked using the funnel plot and Egger's regression test [17]. The heterogeneity of studies was computed using the Cochrane Q-test and I-squared statistic $[18,19]$. Pooled analysis was conducted using a weighted inverse variance random-effects model [20]. Subgroup analysis was conducted using the study region and year of publication. STATA version 11 statistical software was used. Forest plot format was used to present the pooled point prevalence with $95 \% \mathrm{Cl}$. For associations, a log odds ratio was used to decide the association between associated factors and adverse fetal outcomes.

\section{Result}

\section{Characteristics of the included studies}

347 articles were retrieved using a search strategy regarding adverse fetal outcomes and associated factors in Ethiopia at PubMed, Google Scholar, Science Direct, a web of science and other gray literature. After duplicates were expunged, 245 studies remained.

Out of the remaining 245 articles, 193 articles were excluded after review of their titles and abstracts. Therefore, 52 full-text articles were accessed and assessed for inclusion criteria, which resulted in the further exclusion of 35 articles primarily due to reason. As a result, 17 studies were met the inclusion criteria to undergo the final systematic review and meta-analysis (Fig. 1). 


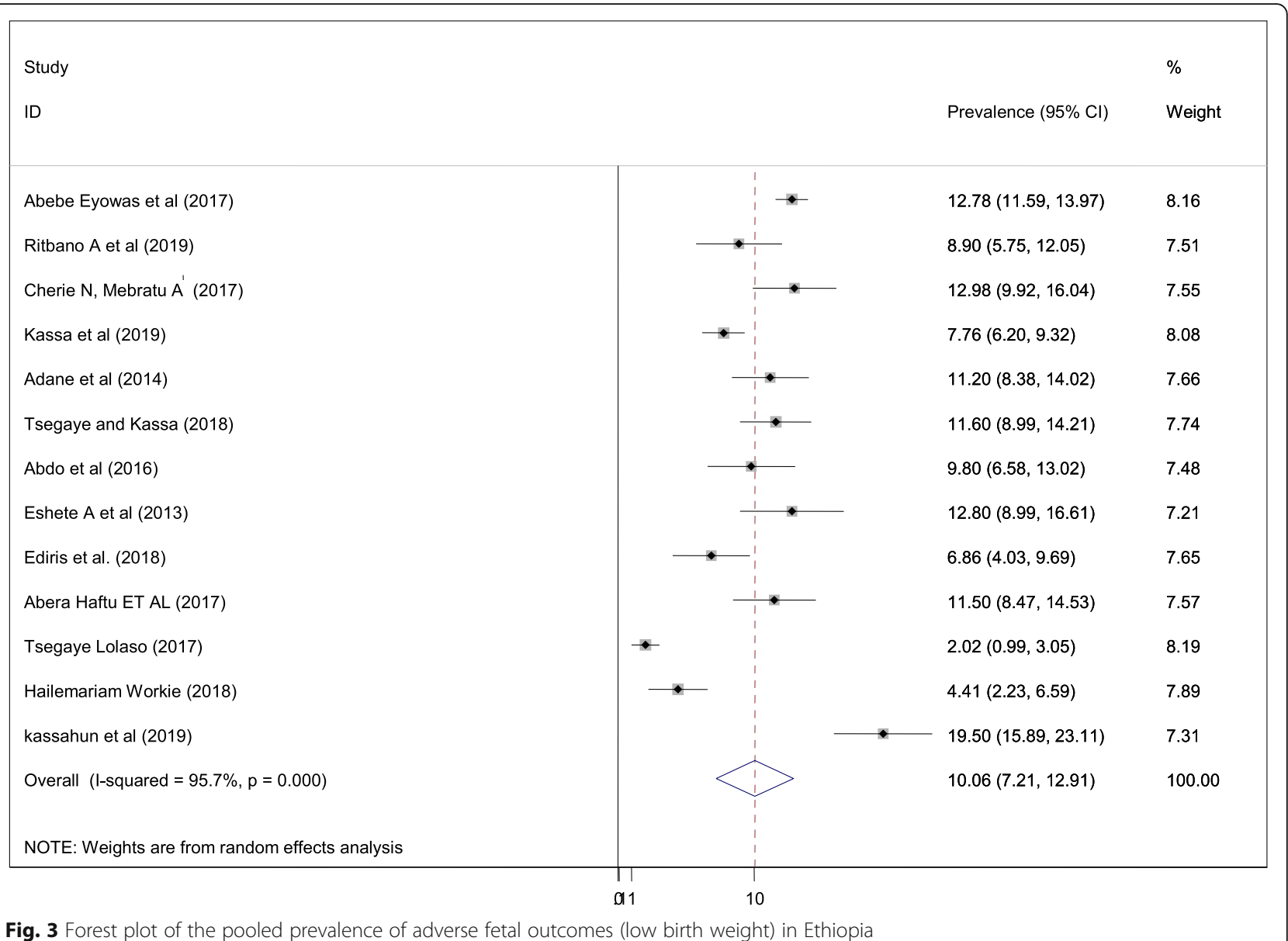

This review is also included factors contributing to adverse neonatal/fetal outcomes; categorized as sociodemographic factors (maternal age, monthly income, residence), obstetric and medical-related factors (pregnancy complication during the current pregnancy, parity, gravidity, status of antenatal care follow up, pregnancyinduced hypertension, antepartum hemorrhage, anemia, multiple pregnancies, bad obstetric history, and rupture of membrane) are the factors associated with adverse pregnancy outcomes [21-36].

All the included studies were conducted from different regions of Ethiopia (Amhara, Oromia, SNNPR (South Nation Nationalities people and representatives), Tigray, Somali and Addis Ababa. Finally, this systematic review and meta-analysis consist of seventeen articles: fourteen studies were cross-sectional and three of them were case-control with a total study participant of 11,280 infants. In this table, the outcome of interest, the number of study participants, prevalence and response rate of the original studies were included. The maximum and minimum sample size amongst the included studies was reported in the Amhara region with a population of
3003 and 295 at Bahirdar and North Wollo respectively (Table 1).

\section{Prevalence of adverse fetal outcomes in Ethiopia}

This study is retrieved seventeen studies with a total population of 11,280 infants. The overall pooled prevalence of adverse fetal outcomes is presented with a forest plot (Fig. 2). Despite, the pooled estimated prevalence of adverse birth outcomes in Ethiopia was 26.88\% (95\% CI; 20.73-33.04; $\mathrm{I}^{2}=97.9 \%, P<0.001$ ), the magnitude of each adverse neonatal outcomes is presented as follows; low birth weight $(10.06 \%)$, preterm birth $(8.76 \%)$, stillbirth (7.09\%) and congenital anomalies accounted (2.55\%).

\section{Pooled meta-analysis of different adverse fetal outcomes categories Pooled prevalence of low birth weight}

The quantified prevalence of low birth weight is presented in a forest plot (Fig. 3). The overall pooled prevalence of low birth weight was $10.06 \%$ (95\% CI; 7.21-12.91; I2 $=95.7 \%, p<0.001)$. In this systematic review and meta-analysis, the included studies were characterized by marked heterogeneity 
Study

ID

Prevalence $(95 \% \mathrm{Cl})$

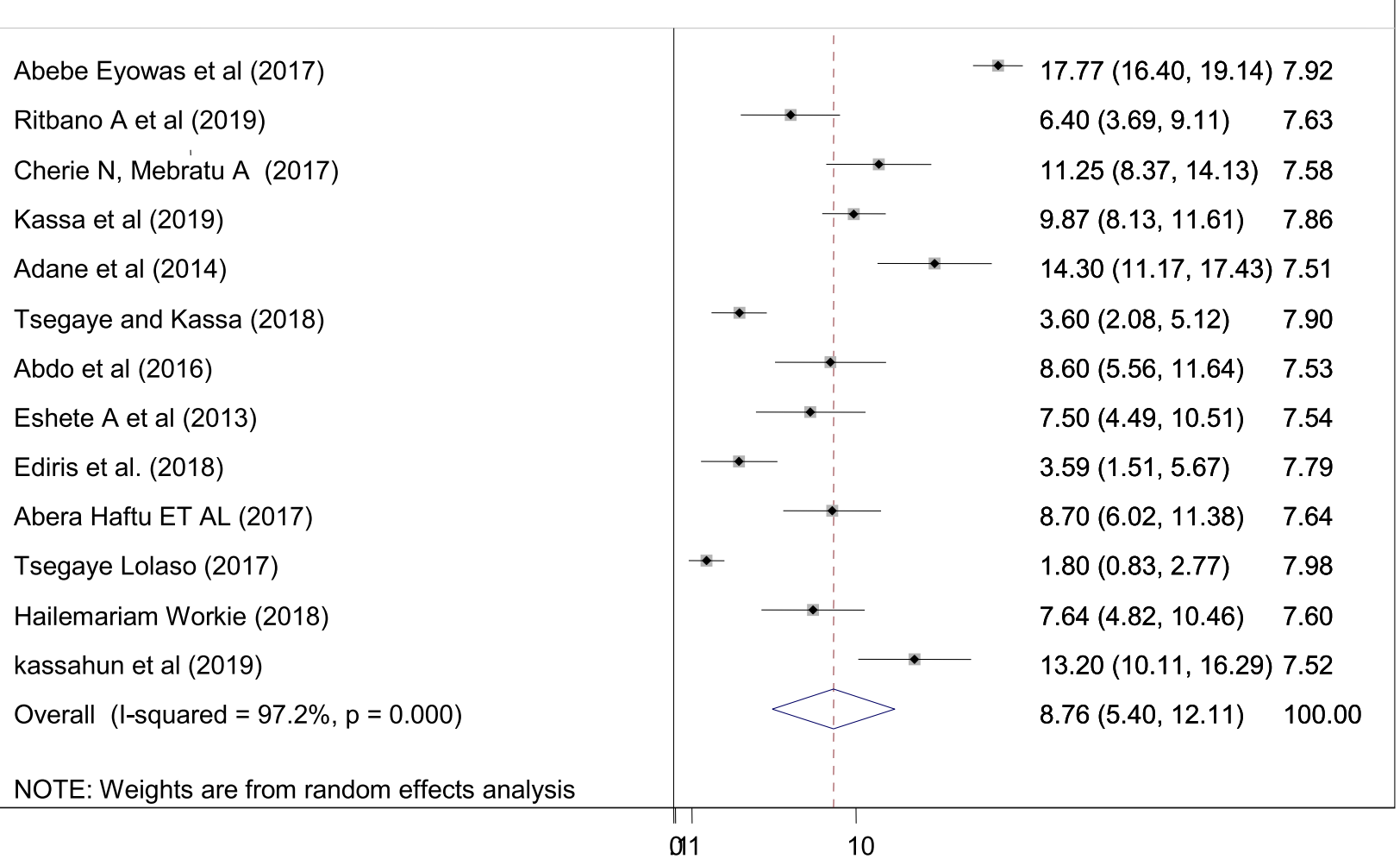

Fig. 4 Forest plot of the pooled prevalence of adverse fetal outcomes (prematurity) in Ethiopia

$\left(\mathrm{I}^{2}=95.7 \% ; p<0.001\right)$. Furthermore, no publication bias was detected using Egger's tests with a p-value of 0.091 .

\section{Pooled prevalence of preterm birth}

The estimated prevalence of preterm birth is presented in a forest plot (Fig. 4). The overall pooled prevalence of prematurity was $8.76 \%$ (95\% CI; 5.4-12.11; I ${ }^{2}=97.2 \%$, $p<0.001)$. In this systematic review and meta-analysis, the included studies were characterized by marked heterogeneity $\left(\mathrm{I}^{2}=97.2 \% ; p<0.001\right)$. Furthermore, no publication bias was detected using Egger's tests with a $p$ value of 0.26 .

\section{Pooled prevalence of stillbirth}

The estimated prevalence of fetal death is presented in a forest plot (Fig. 5). The overall pooled prevalence of fetal death was 7. 09\% (95\% CI; 4.93-9.26; $\mathrm{I}^{2}=95.5 \%, p<$ $0.001)$. In this systematic review and meta-analysis, the included studies were characterized by marked heterogeneity $\left(\mathrm{I}^{2}=95.5 \%, p<0.001\right)$. Furthermore, low publication bias was detected using Egger's tests with a $p$ value of 0.03 .

\section{Pooled prevalence of congenital defect}

The estimated prevalence of congenital defects is presented in a forest plot (Fig. 6). The overall pooled prevalence of congenital defect was $2.55 \%$ (95\% CI; 1.41-3.69; $\left.\mathrm{I}^{2}=81.5 \%, p<0.001\right)$. In this systematic review and meta-analysis, the included studies were characterized by marked heterogeneity $\left(\mathrm{I}^{2}=81.5 \%, p<0.001\right)$. Furthermore, possibility of publication bias was detected using Egger's tests with a $p$-value of 0.006 .

\section{Publication bias}

A funnel plot was assessed for asymmetry distribution of adverse fetal outcomes by visual inspection (Fig. 7). Egger's regression test showed with a p-value of 0.522 showed that the absence of publication bias.

\section{Subgroup analysis}

Subgroup analysis was employed with the evidence of heterogeneity. Hence the Cochrane $\mathrm{I}^{2}$ statistic $=97.9 \%$, $P<0.001)$ with evidence of marked heterogeneity. Therefore subgroup analysis was done by publication year and study area (Table 2). 
Study

ID

Abebe Eyowas et al (2017)

Ritbano A et al (2019)

Cherie N, Mebratu A (2017)

Kassa et al (2019)

Adane et al (2014)

Tsegaye and Kassa (2018)

Abdo et al (2016)

Eshete A et al (2013)

Ediris et al. (2018)

Abera Haftu ET AL (2017)

Tsegaye Lolaso (2017)

Mekonnen M, et al (2018)

Hailemariam Workie (2018)

kassahun et al (2019)

Overall (I-squared $=95.5 \%, p=0.000)$

NOTE: Weights are from random effects analysis
Prevalence $(95 \% \mathrm{Cl}) \quad$ Weight

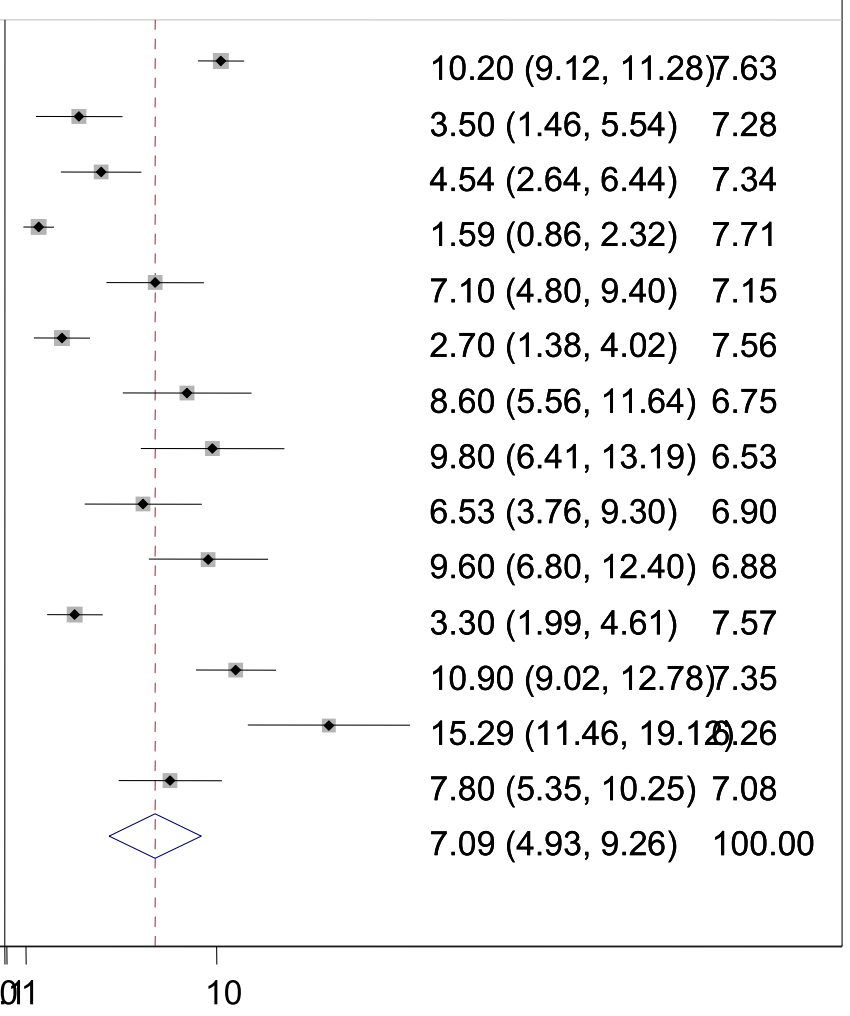

Fig. 5 Forest plot of the pooled prevalence of adverse fetal outcomes (still birth) in Ethiopia

\section{Associated factors for adverse fetal outcomes}

In this systematic review and meta-analysis; rural residency, lack of antenatal care follow up, pregnancy, current pregnancy complication, and advanced maternal age were the factors for adverse fetal outcomes (Table 3).

Women who were in rural residency $(\mathrm{AOR}=2.31 ; 95 \%$ CI: 1.64-3.24) 2.3 times more likely to have adverse fetal outcomes than women who were living in an urban area.

Women who hadn't antenatal care follow up (AOR = 3.84; 95\% CI: 2.76-5.35) 3.84 times more likely to have adverse fetal outcome than women who had antenatal care follow up.

Women who had current pregnancy complications $(\mathrm{AOR}=4.98$; 95\% CI: 2.24-11.07) nearly 5 times more likely to have adverse fetal outcome than women who hadn't current pregnancy complication.

The odds of having advanced maternal age $\geq 35$ $(\mathrm{AOR}=2.72 ; 95 \% \mathrm{CI}: 1.62-4.58)$, had a high chance of developing adverse fetal outcome.

In this study women who had pregnancy-induced hypertension $(\mathrm{AOR}=7.27 ; 95 \% \mathrm{CI}$ : 3.95-13.39), were
7.27 times more likely to develop adverse fetal outcomes than their counterparts.

\section{Discussion}

Pregnancy outcomes in low- and many middle-income countries are far worse than those in high-income countries. In this systematic review and Meta-analysis, the pooled prevalence of adverse fetal outcomes in Ethiopia was $26.88 \%$ (95\% CI; 20.73-33.04). The most common adverse birth outcome categories were low birth weight of $10.06 \%$ (7.21-12.91), and preterm birth $8.76 \%$ (5.412.11).

This meta-analysis was estimated the national prevalence of stillbirth among adverse fetal outcomes in Ethiopia. Hence, the overall pooled prevalence of stillbirth was 7. 09\% (4.93-9.26). This review finding is lower than the study conducted in India [25.3\%], Pakistan [56.9\%] and Guatemala [19.9\%] [38, 39]. This discrepancy might be due to the study participants included in this systematic review and meta-analysis were reviewing in a single country with multiple original studies; might have lower representatives as 


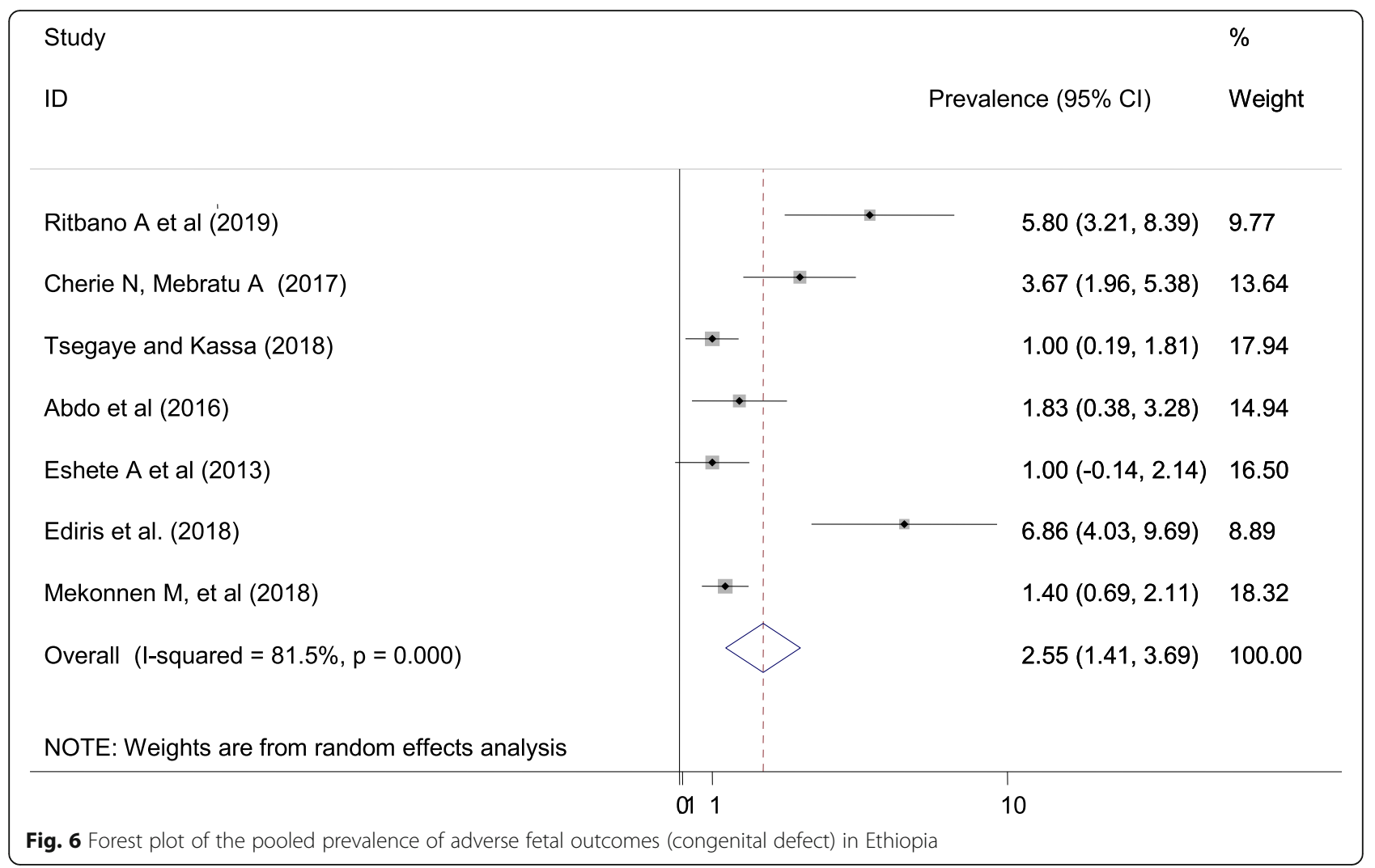

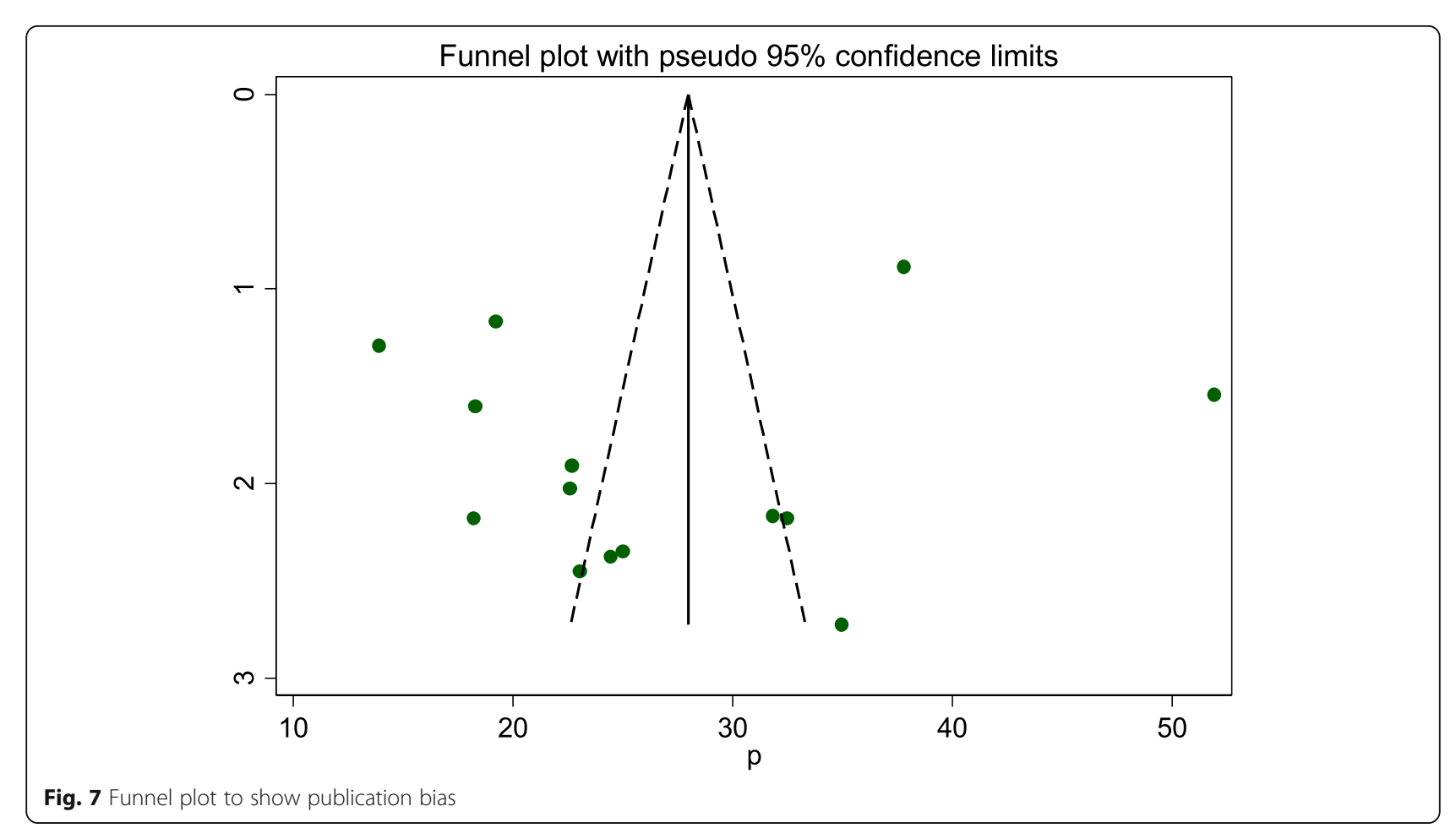


Table 2 Sub group analysis on the prevalence of adverse fetal outcomes in Ethiopia

\begin{tabular}{lllllll}
\hline Variables & subgroup & No. of studies & Model & Prevalence $(95 \% \mathrm{Cl})$ & $\mathrm{I}^{2}(\%)$ & $P$ value \\
\hline Publication year & $2013-2016$ & 3 & random & $23.3(20.8,25.8)$ & 97.9 & $<0.001$ \\
& $2016-2019$ & 11 & random & $27.83(20.4-35.3)$ & 98.4 & $<0.001$ \\
Study area & SNNPR & 4 & random & $18.4(14.3,22.6)$ & 81.7 & $<0.001$ \\
& Amhara & 6 & random & $27.87(20.2,35.6)$ & 97.3 & $<0.001$ \\
& Tigray & 2 & Fixed & $23.6(20.6,26.66)$ & 0 & 0.437 \\
& Others $^{\text {a }}$ & 2 & Random & $43.6(27,60.2)$ & 96.6 & $<0.001$ \\
\hline
\end{tabular}

Others $^{\mathrm{a}}$ (Oromia and Somali)

compared to studies conducted at a global level consisting of many countries at a point.

This review was estimated the overall prevalence of preterm (prematurity) among adverse fetal outcomes in Ethiopia. Hence, the overall pooled prevalence of preterm was $8.76 \%(5.4-12.11)$. This study finding is in line with the study done in Asia [10.4\%], North America [11.2\%], Sub-Saharan Africa [12\%], Nigeria [11.4\%], South Korea [7.1\%], Nebraska [5.54\%] and Indonesia [10.4\%] [40-42]. This finding is consistent with Asian and African countries, because of the health package and health care system towards maternal and neonatal health is nearly similar. Besides, now a day's countries are implementing different strategies and preventive modalities to preterm birth in collaboration with governmental and non-governmental organizations for African countries including Ethiopia, as a result, this finding is lower as compared to the WHO target level of prematurity for the contribution of neonatal mortality and morbidity.

This review was estimated the overall prevalence of congenital defects among adverse fetal outcomes in Ethiopia. Hence, the overall pooled prevalence of congenital defects was $2.55 \%(2.41-3.69)$. This review finding is lower than the study done in sub-Saharan Africa [20\%], and Nigeria [6.3\%] [43, 44]. The discrepancy of these study findings may be due to the association of the participants in terms of different characteristics; such as residence, socio-demographic factors, behavioral factors, genetic factors, environmental factors, and socioeconomic status. Besides, iron-folic acid supplementation during pregnancy is decreasing the congenital anomalies by $70 \%$, therefore, in Ethiopia, the supplementation is highly practicing and implementing now a day's widely.

This review was estimated the overall prevalence of low birth weight among adverse birth outcomes in Ethiopia. Hence, the overall pooled prevalence of low birth weight was $10.06 \%$ (7.21-12.91). This study finding is in line with the study done in Indonesia [12.9\%], Armenia [9.0\%, higher than the study conducted in Nigeria [6.3\%] and lower than the study done in Kenya [12.3\%], Tanzania (13.9\%), South Africa [38.54\%] [4548]. Low birth weight has different known and idiopathic risk factors; such as environmental and lifestyle risk factors, fetal risk factors, obstetric related factors, medicalrelated factors, and maternal \& family sociodemographic risk factors. Having the supremacy of the above-motioned risk factors in each country may be increasing the magnitude of the preterm birth even death may have happened secondary to prematurity of the baby.

The odds of having advanced maternal age $\geq 35$ years nearly three times to have adverse fetal outcomes. This finding is in line with the study done in Cameroon [49], low income countries [39], India [50], Nigeria [51], African lake regions [52], Uganda [53]. This might be due to the age of the women directly linked with parity. Therefore, high parity women at risk for developing different labor and delivery complications that lead to both fetal and maternal outcomes due to the laxity of the uterus in repeated and short inter interval pregnancy.

The odds of having pregnancy-induced hypertension were nearly three times to have adverse birth outcomes. This finding is in line with the study done in Cameroon [49], Kenya [54], India [50], Nigeria [51], and Bangladesh [55]. This might

Table 3 Summary of associated risk factors for adverse birth outcome in Ethiopia

\begin{tabular}{|c|c|c|c|c|c|c|}
\hline Variables & Model & $\begin{array}{l}\text { Publication bias } \\
\text { Egger test }\end{array}$ & Status of heterogeneity & $\mathrm{AOR}(95 \% \mathrm{Cl})$ & $I^{2}(\%)$ & $P$ value \\
\hline Rural residency & Random & 0.001 & Low heterogeneity & $2.31(1.64,3.24)$ & 32.1 & 0.183 \\
\hline Current pregnancy complication & Random & 0.952 & moderate heterogeneity & $4.98(2.24,11.07)$ & 85.9 & $<0.001$ \\
\hline Not having antenatal care & Random & 0.136 & Low heterogeneity & $3.84(2.76,5.35)$ & 23.1 & 0.238 \\
\hline Advanced maternal age $\geq 35$ & Random & 0.008 & Moderate heterogeneity & $2.72(1.62,4.58)$ & 55.6 & 0.08 \\
\hline Pregnancy induced-hypertension & Fixed & 0.065 & No heterogeneity & $7.27(3.95,13.39)$ & 0 & 0.868 \\
\hline
\end{tabular}


be due to endothelial cell injury and vasoconstriction of blood vessels which causes placental insufficiency.

Pregnancy complication is one of the associated risk factors in this meta-analysis. Having pregnancy complications was almost five times more likely to develop adverse fetal outcomes. This study finding is in line with the study done in Bangladesh [55]. Brazil [56], Kenya [57] and China [58]. The possible reason might be due to women who have current pregnancy complications such as; premature rupture of membrane, antepartum hemorrhage, and abnormal labor and pregnancy are the most common pregnancy and labor complications that cause preterm birth, stillbirth, and low birth weight.

Lack of antenatal care follow up is the associated risk factor for adverse fetal outcomes in this meta-analysis. Having no ANC follow up was four times more likely to develop adverse birth outcomes. This study finding is in line with the study done in Tanzania [59], and Gambia [60]. This might be due to During ANC follow up women will have a chance to access information related to danger signs of pregnancy. Having regular ANC follow up will also help a pregnant woman seek early treatment for her potential pregnancy-related problems [27].

The odds of living in rural were two times more likely to develop adverse fetal outcomes. This study finding is in line with the study done in China [61], and Brazil [62]. This might be due to women who live in rural areas aren't getting health care services comprehensively and they are less likely to be informed about the danger sign and complication of pregnancy, labor, and delivery. Furthermore, cultural behaviors in rural areas have a great effect on the nutritional status of women through the prohibition of essential foods and or drinks [36]. Publication bias has happened if one or more of the following has existed: selection bias, true heterogeneity, artifact, and chances are the main sources of publication bias. Large studies are likely to be published regardless of statistical significance because these studies involve large commitments of time and resources whereas Small studies are at greatest risk for being lost, because of the small sample size. In this study publication bias was not detected (Eggers, $p$ value $=0.522$ ) of the polled estimated prevalence of adverse fetal outcomes.

\section{Limitations of the study}

Including papers only published by the English language and accessing only hospital-based studies was the restraint of the study. It might lack national representativeness because no data were from all regions.

\section{Conclusion}

In this study, the overall pooled prevalence of adverse fetal outcomes in Ethiopia was high. Rural in residency, lack of antenatal care follow up, pregnancy-induced hypertension, advanced maternal age $\geq 35$, and having a current complication of pregnancy were the factors associated with adverse fetal outcomes. Therefore, based on the study findings, the authors recommend particular emphasis shall be given to have regular antenatal care follow up, health education, early detection, and intervention of obstetric complications. Creating awareness of women on the effect of pregnancy at an advanced age, and providing timely and focused antenatal care (ANC) follow up to all pregnant women are very crucial to reduce the magnitude of the problem.

\section{Abbreviations \\ Cl: Confidence Interval; EDHS: Ethiopian demographic and health survey; EMDHS: Ethiopian Mini demographic and health survey; LBW: Low Birth Weight; OR: Odd Ratio; SNNPR: South Nation Nationalities and Peoples region}

\section{Acknowledgements \\ Not applicable.}

\section{Authors' contributions}

All authors (GG,AD\& BA, ) critically reviewed, provided substantive feedback and contributed to the intellectual content of this paper and made substantial contributions to the conception, conceptualization and manuscript preparation of this systematic review. All authors read and approved the final manuscript.

\section{Funding}

Not applicable.

\section{Availability of data and materials}

All related data has been presented within the manuscript. The dataset supporting the conclusions of this article is available from the authors on request.

Ethics approval and consent to participate

Not applicable.

\section{Consent for publication}

Not applicable.

\section{Competing interests}

The authors declared that they have no competing interests.

\section{Author details}

'Department of Midwifery, College of health sciences, Woldia University, Woldia, Ethiopia. ${ }^{2}$ Department of Medical laboratory science, College of health sciences, Woldia University, Woldia, Ethiopia. ${ }^{3}$ Department of Nursing, College of health sciences, Woldia University, Woldia, Ethiopia.

Received: 13 February 2020 Accepted: 27 May 2020

Published online: 03 June 2020

\section{References}

1. You D, Hug L, Ejdemyr S, Idele P, Hogan D, Mathers C, Gerland P, New JR, Alkema L. United Nations Inter-agency Group for Child Mortality Estimation (UN IGME). Global, regional, and national levels and trends in under-5 mortality between 1990 and 2015, with scenario-based projections to 2030: a systematic analysis by the UN Inter-agency Group for Child Mortality Estimation. Lancet. 2015;386(10010):2275-86.

2. Rezende Chrisman J, Mattos IE, Koifman RJ, Koifman S, Moraes Mello Boccolini P, Meyer A. Prevalence of very low birthweight, malformation, and low Apgar score among newborns in Brazil according to maternal urban or rural residence at birth. J Obstet Gynaecol Res. 2016;42(5):496-504.

3. Azoumah K, Djadou K, Aboubakari A, Bothon A, Agbodjan-Djossou O, Agbèrè A. General medicine: open evaluation of the glycemia of low- 
weight newborns within the 24th hour of life at Lome university hospital (Togo). Arch Pediatr. 2011;18(10):1037-43.

4. Seyum T, Ebrahim E. Proportion of neonatal hypothermia and associated factors among new-borns at Gondar University teaching and Refferal hospital, Northwest Ethiopia: a hospital based cross sectional study. Gen Med. 2015;2015.

5. Hack M, Klein NK, Taylor HG. Long-term developmental outcomes of low birth weight infants. Futur Child. 1995:176-96.

6. Gutbrod T, Wolke D, Soehne B, Ohrt B, Riegel K. Effects of gestation and birth weight on the growth and development of very low birthweight small for gestational age infants: a matched group comparison. Arch Dis Child Fetal Neonatal Ed. 2000;82(3):F208-F14.

7. WHO. World health ranking: Ethiopia low birth weight. 2014.

8. WHO. WHA Global Nutrition Targets 2025: Low Birth Weight Policy Brief. p. 2014.

9. Liu L, Liu JM, Liu YH, Li ZW, Ye RW, Zheng JC, Li Z. Prevalence of preterm birth among singletons in 10 counties (cities) of China, 1993-2005. Zhonghua Liu Xing Bing Xue Za Zhi. 2007;28(11):1051-4.

10. Mokuolu OA, Suleiman B, Adesiyun O, Adeniyi A. Prevalence and determinants of pre-term deliveries in the University of Ilorin Teaching Hospital. Ilorin Nigeria Pediatr Rep. 2010;2(1):e3.

11. Silveira MF, Victora CG, Barros AJ, Santos IS, Matijasevich A, Barros FC. Determinants of preterm birth: Pelotas, Rio Grande do Sul state, Brazil, 2004 birth cohort. Cad Saude Publica. 2010;26(1):185-94.

12. Say L. WHO DoRHaR, editor. National, regional, and worldwide estimates of stillbirth rates in 2009 with trends since 1995. Geneva: WHO. p. 2011.

13. Mekonnen Y, Tensou B, Telake DS, Degefie T, Bekele A. Neonatal mortality in Ethiopia: trends and determinants. BMC Public Health. 2013;13(1):483.

14. Lawn JE, Gravett MG, Nunes TM, Rubens CE, Stanton C. Global report on preterm birth and stillbirth (1 of 7): definitions, description of the burden and opportunities to improve data. BMC Pregnancy Childbirth. 2010;10(1): S1.

15. Mathers C, Stevens G, Hogan D, Mahanani WR, Ho J. Global and regional causes of death: patterns and trends, 2000-15. In Disease Control Priorities: Improving Health and Reducing Poverty. 3rd edition. The International Bank for Reconstruction and Development/The World Bank; 2017.

16. Peters M, Godfrey C, Mclnerney P, Soares C, Hanan K, Parker D. The Joanna Briggs institute Reviewers' manual 2015: methodology for JBI scoping reviews; 2015.

17. Egger M, Smith GD, Schneider M, Minder C. Bias in meta-analysis detected by a simple, graphical test. BMJ. 1997;315(7109):62934.

18. Ioannidis J. Interpretation of tests of heterogeneity and bias in metaanalysis. J Eval Clin Pract. 2008;14(5):951-7.

19. Higgins J, Thompson SG. Quantifying heterogeneity in a meta-analysis. Stat Med. 2002;21(11):1539-58.

20. Borenstein M, Hedges LV, Higgins J, Rothstein HR. A basic introduction to fixed-effect and random-effects models for meta-analysis. Res Synth Methods. 2010;1(2):97-111.

21. Eyowas FA, Negasi AK, Aynalem GE, Worku AG. Adverse birth outcome: a comparative analysis between cesarean section and vaginal delivery at Felegehiwot Referral Hospital, Northwest Ethiopia: a retrospective record review. Pediatric health, medicine and therapeutics. 2016;7:65.

22. Abdo RA, Halil HM, Birhanu LZ, Defara DA, Kebede BA. Prevalence and Associated Factors of Adverse Birth Outcome Among Deliveries at Butajira Hospital,Southern Ethiopia. J Gynecol Womens Health. 2019;15(4):555920. https://doi.org/10.19080/JGWH.2019.15.555920.

23. Kebede AS, Muche AA, Alene AG. Factors associated with adverse pregnancy outcome in Debre Tabor town, Northwest Ethiopia: a case control study. BMC Res Notes. 2018;11(1):820.

24. Cherie N, Mebratu A. Adverse birth out comes and associated factors among delivered mothers in Dessie referral hospital, north East Ethiopia. J Womens Health Reprod Med. 2017;1(1):4.

25. Kassa GM, Arowojolu AO, Odukogbe AA, Yalew AW. Adverse neonatal outcomes of adolescent pregnancy in Northwest Ethiopia. PLOS One. 2019; 14(6):e0218259.

26. Gebremeskel F, Gultie T, Kejela G, Hailu D, Workneh Y. Determinants of adverse birth outcome among mothers who gave birth at hospitals in Gamo Gofa zone, southern Ethiopia: a facility based case control study. Qual Prim Care. 2017;25(5):259-66.

27. Adane AA, Ayele TA, Ararsa LG, Bitew BD, Zeleke BM. Adverse birth outcomes among deliveries at Gondar University hospital, Northwest Ethiopia. BMC Pregnancy Childbirth. 2014 Dec;14(1):90
28. Tsegaye B, Kassa A. Prevalence of adverse birth outcome and associated factors among women who delivered in Hawassa town governmental health institutions, South Ethiopia, in 2017. Reprod Health. 2018 Dec;15(1): 193.

29. Abdo RA, Endalemaw TB, Tesso FY. Prevalence and associated factors of adverse birth outcomes among women attended maternity ward at Negest Elene Mohammed Memorial General Hospital in Hosanna Town, SNNPR, Ethiopia. J Women's Health Care. 2016;5(4).

30. Yeshialem E, Abera M, Tesfay A. Determinants of adverse pregnancy outcomes among mothers who gave birth from jan 1-dec 31/2015 in jimma university specialized hospital, case control study, 2016. Ethiop J Reprod Health. 2019;11(1):10.

31. Eshete A, Birhanu D, Wassie B. Birth outcomes among laboring mothers in selected health facilities of north Wollo zone, Northeast Ethiopia: A facility based cross-sectional study. Health. 2013:5:1141-50.

32. Ediris M, Belachew T, Yadassa F, Getu K. Disparities in adverse pregnancy outcomes between advanced maternal age and younger age in Ethiopia: institution based comparative cross-sectional study. Int J Nursing and Mid 2018:10(6):54-61.

33. Tesfay A, Abera H, Brhane G. Assessment of Magnitude and Associated Factors of Adverse Birth Outcomes among Deliveries at Suhul Hospital Shire, Tigray, Ethiopia From September, 2015 to February, 2016. Biomed J Sci Tech Res. 2017. BJSTR. MS.ID.000619;1(7). https://doi.org/10.26717/BJSTR. 2017.01 .000619

34. Lolaso T, Dessie Y, Oljira L. Magnitude of adverse birth outcome and associated factors among mothers delivering in Public Health Institutions of Kembata Tembaro Zone, Southern Ethiopia (Doctoral dissertation, Haramaya University).

35. Workie H. Adverse neonatal outcomes and associated risk factors in public and private hospitals of Mekelle city, Tigray, Ethiopia: Unmatched casecontrol study. Neonat Pediatr Med. 2018;04(8)

36. Kassahun EA, Mitku HD, Getu MA. Adverse birth outcomes and its associated factors among women who delivered in north Wollo zone, Northeast Ethiopia: a facility based cross-sectional study. BMC Res Notes. 2019;12(1):357.

37. Mekonnen M, Bekele K, Tasew A, Beker J, Kadir M, et al. Prevalence and risk factor for poor pregnancy outcome among married women, in Fafan zone, Somali region, eastern Ethiopia. Health Sci J. 2018;12(6):610.

38. Blencowe H, Cousens S, Jassir FB, Say L, Chou D, Mathers C, Hogan D, Shiekh S, Qureshi ZU, You D, Lawn JE. National, regional, and worldwide estimates of stillbirth rates in 2015, with trends from 2000: a systematic analysis. Lancet Glob Health. 2016;4(2):e98-108.

39. Saleem S, Tikmani SS, McClure EM, Moore JL, Azam SI, Dhaded SM, Goudar SS, Garces A, Figueroa L, Marete I, Tenge C. Trends and determinants of stillbirth in developing countries: results from the global Network's population-based birth registry. Reprod Health. 2018;15(1):100.

40. Chawanpaiboon S, Vogel JP, Moller AB, Lumbiganon P, Petzold M, Hogan D, Landoulsi S, Jampathong N, Kongwattanakul K, Laopaiboon M, Lewis C. Global, regional, and national estimates of levels of preterm birth in 2014: a systematic review and modelling analysis. Lancet Glob Health. 2019;7(1):e37-46.

41. Choi Y, Lee G, Song IG, Kim OJ, Park SM. Prevalence of adverse birth outcomes and disparity of unmarried women in South Korea: a systematic review. J Glob Health Rep. 2018;2:e2018008.

42. Su D, Samson K, Garg A, Hanson C, Berry AL, Lin G, Qu M. Birth history as a predictor of adverse birth outcomes: evidence from state vital statistics data. Prev Med Rep. 2018;11:63-8.

43. Wonkam A. The Burden of Birth Defects and Genetic Disease in SubSaharan Africa. https://doi.org/10.1093/med/9780195374759.003.0037.

44. Ajao AE, Adeoye IA. Prevalence, risk factors and outcome of congenital anomalies among neonatal admissions in OGBOMOSO, Nigeria. BMC Pediatrics. 2019;19(1):88.

45. Oladeinde HB, Oladeinde OB, Omoregie R, Onifade AA. Prevalence and determinants of low birth weight: the situation in a traditional birth home in Benin City, Nigeria. Afr Health Sci. 2015;15(4):1123-9.

46. Tshotetsi L, Dzikiti L, Hajison P, Feresu S. Maternal factors contributing to low birth weight deliveries in Tshwane District, South Africa. PloS one. 2019; 14(3):e0213058.

47. Goldenberg RL, McClure EM. Improving birth outcomes in low- and middleincome countries. 2017:2387-8.

48. Mahumud RA, Sultana M, Sarker AR. Distribution and determinants of low birth weight in developing countries. J Prev Med Public Health. 2017;50(1):18. 
49. Tolefac PN, Tamambang RF, Yeika E, Mbwagbaw LT, Egbe T. Ten years analysis of stillbirth in a tertiary hospital in sub-Sahara Africa: a case control study. BMC Res Notes. 2017;10(1):447.

50. Shetty MB, Krupa B, Malyala M, Swarup A, Pathadan DS, Pocha S. Preterm birth: associated risk factors and outcome in tertiary care center. Int J Reprod Contracept Obstetr Gynecol. 2017;6(8):3271-4.

51. Butali A, Ezeaka C, Ekhaguere O, Weathers N, Ladd J, Fajolu I, Esezobor C, Makwe C, Odusanya B, Anorlu R, Adeyemo W. Characteristics and risk factors of preterm births in a tertiary center in Lagos, Nigeria. Pan Afr Med J. 2016;24(1).

52. Akombi BJ, Ghimire PR, Agho KE, Renzaho AM. Stillbirth in the African Great Lakes region: a pooled analysis of demographic and health surveys. PLoS One. 2018;13(8):e0202603.

53. Kujala S, Waiswa P, Kadobera D, Akuze J, Pariyo G, Hanson C. Trends and risk factors of stillbirths and neonatal deaths in eastern Uganda (1982-2011): a cross-sectional, population-based study. Tropical Med Int Health. 2017; 22(1):63-73.

54. Mogire GK. Factors Associated with Low Birth Weight deliveries in Pumwani Maternity Hospital, Nairobi-Kenya (Doctoral dissertation).

55. Khanam R, Ahmed S, Creanga AA, Begum N, Koffi AK, Mahmud A, Rosen H, Baqui AH. Antepartum complications and perinatal mortality in rural Bangladesh. BMC Pregnancy Childbirth. 2017;17(1):81.

56. Lansky S, Friche AA, Silva AA, Campos D, Bittencourt SD, Carvalho ML, Frias PG, Cavalcante RS, Cunha AJ. Birth in Brazil survey: neonatal mortality, pregnancy and childbirth quality of care. Cadernos de saude publica. 2014; 30:S192-207.

57. Muchemi OM, Echoka E, Makokha A. Factors associated with low birth weight among neonates born at Olkalou District hospital, central region, Kenya. Pan Afr Med J. 2015;20.

58. Chen Y, Li G, Ruan Y, Zou L, Wang X, Zhang W. An epidemiological survey on low birth weight infants in China and analysis of outcomes of full-term low birth weight infants. BMC Pregnancy Childbirth. 2013;13.

59. Watson-Jones D, Weiss HA, Changalucha JM, Todd J, Gumodoka B, Bulmer J, Balira R, Ross D, Mugeye K, Hayes R, Mabey D. Adverse birth outcomes in United Republic of Tanzania: impact and prevention of maternal risk factors. Bull World Health Organ. 2007;85:9-18.

60. Jammeh A, Vangen S, Sundby J. Stillbirths in rural hospitals in the Gambia: a cross-sectional retrospective study. Obstet Gynecol Int. 2010;2010.

61. Lin L, Wei Y, Zhu W, Wang C, Su R, Feng H, Yang H. Prevalence, risk factors and associated adverse pregnancy outcomes of anaemia in Chinese pregnant women: a multicentre retrospective study. BMC Pregnancy Childbirth. 2018;18(1):111.

62. Juliana C. Adverse pregnancy outcomes and maternal urban or rural residence at birth in Brazil. J Obstet Gynecology. 2016:42:496-504.

\section{Publisher's Note}

Springer Nature remains neutral with regard to jurisdictional claims in published maps and institutional affiliations.

Ready to submit your research? Choose BMC and benefit from:

- fast, convenient online submission

- thorough peer review by experienced researchers in your field

- rapid publication on acceptance

- support for research data, including large and complex data types

- gold Open Access which fosters wider collaboration and increased citations

- maximum visibility for your research: over $100 \mathrm{M}$ website views per year

At $\mathrm{BMC}$, research is always in progress.

Learn more biomedcentral.com/submissions 